Journal of Applied Pharmaceutical Science Vol. 6 (05), pp. 097-101, May, 2016

Available online at http://www.japsonline.com

DOI: $10.7324 / J A P S .2016 .60515$

ISSN 2231-3354 (cc)) BY-NC-SA

\title{
In vitro $\alpha$-glucosidase inhibition and antioxidant activities of partially purified Antidesma bunius fruit and Gynura nepalensis leaf extracts
}

\author{
Noel Quiming*, Joannes Luke Asis, Marilou Nicolas, Dhennis Versoza, Michael Russelle Alvarez \\ Department of Physical Sciences and Mathematics, College of Arts and Sciences, University of the Philippines Manila, Manila City, Philippines.
}

\begin{tabular}{l} 
ARTICLE INFO \\
\hline Article history: \\
Received on: 04/02/2016 \\
Revised on: 10/03/2016 \\
Accepted on: $20 / 04 / 2016$ \\
Available online: $28 / 05 / 2016$ \\
\hline Key words: \\
Diabetes mellitus, Antidesma \\
bunius, Gynura nepalensis, \\
partial purification, $\alpha-$ \\
glucosidase inhibition \\
activity, antioxidant activity.
\end{tabular}

\section{INTRODUCTION}

Type 2 diabetes mellitus is a metabolic disorder caused by chronic hyperglycemia due to insulin resistance and loss of $\beta$ cell function. Its complete mechanism has not yet been elucidated; it is believed to be caused by a variety of genetic and environmental factors (Wilcox, 2005). In 2011, the number of cases of all types of diabetes was estimated to be 366 million worldwide $(8.30 \%$ of the world population) while in the Philippines, the estimate was 4.2 million ( $8.2 \%$ prevalence) and are expected to rise in the future (Whiting et al., 2011). Poor management of diabetes may lead to complications which

\footnotetext{
* Corresponding Author

Noel Quiming, Department of Physical Sciences and Mathematics, College of Arts and Sciences, University of the Philippines Manila, Manila City, Philippines.Email:noel_quiming@yahoo.com
}

include cardiovascular diseases, retinopathy, nephropathy, neuropathy, and peripheral gangrene-making this disease the eighth leading cause of mortality in the Philippines (Chang et al., 2013). Current drugs used in the treatment of diabetes include sulfonylureas, biguanides, thiazolidinedione, and $\alpha$-glucosidase inhibitors, sodium-glucose co-transporter inhibitors, glucagon-like peptide-1 analogues and dipeptidyl peptidase-IV inhibitors. These may be costly, inadequate, and have side effects (Chang et al., 2013; Kimmel et al., 2005; White, 2008; Abdul-Ghani and Defronzo, 2011; Garber, 2011). $\alpha$-glucosidase inhibitors such as the drugs acarbose, miglitol, and voglibose can decrease hyperglycemia by decreasing the digestion and absorption of glucose in the intestines via inhibition of $\alpha$-glucosidases (Mogensen, 2007). Antioxidants, such as vitamin E and flavonoids, have also proven beneficial to diabetics as they decrease the risk of complications (Bonnefont-Rousselot, 2004). 
In various studies, it has been shown that antidiabetic drugs and antioxidants delayed or prevented the onset of type 2 diabetes mellitus in patients with impaired glucose tolerance (Montonen et al., 2004; Kawamori, 2009; Phung et al., 2011). More than 400 plants, such as Momordica charantia and Gynura spp. have been shown to have antidiabetic activities in vitro and in vivo (Singh et al., 2011; Tan et al., 2013; Algariri et al., 2013; Deng et al., 2011; Liu et al., 2010; Li et al., 2009). Metformin, a biguanide widely used in the treatment of type 2 diabetes, has been developed based on a biguanide in French lilac (Chang et al., 2013). Major classes of phytochemicals which have been shown to have antidiabetic effects are alkaloids, flavonoids, glycosides/steroids/terpenoids, polysaccharides/ proteins, and miscellaneous compounds (Lamba et al., 2000). Various plant extracts have already been shown to exhibit positive effects in diabetic assays, particularly $\alpha$-glucosidase inhibitory and antioxidant activities (Lawag et al., 2012; Misbah et al., 2013; Wang et al., 2013; Shihabudeen et al., 2011; Apea-Bah et al., 2009).

Leaves of A. bunius, locally known as bignay, have been shown to possess $\alpha$-glucosidase inhibitory activity (Lawag et al., 2012). G. nepalensis, locally known as ashitaba, has been used traditionally to control hyperglycemia in diabetic patients but no experiment has been done to study its antihyperglycemic or antioxidant properties.

The study aims to determine $\alpha$-glucosidase inhibitory and antioxidant activities of partially purified ethanolic extracts of $A$. bunius fruits and $G$. nepalensis leaves using in vitro assays, as well as determine the phytochemical constituents of the most active fractions.

\section{MATERIAL AND METHODS}

\section{Plant samples}

Ripe A. bunius fruits and $G$. nepalensis leaves were obtained from local plant cultivators (Luzon, Philippines). These were authenticated by the Botany Division, National Museum, Philippines.

\section{Extraction of $A$. bunius fruits and $G$. nepalensis leaves}

Two kilograms $(2 \mathrm{~kg})$ A. bunius fruits and $100 \mathrm{~g}$ dried $G$. nepalensis leaves were powdered using an electric blender, then each were extracted twice with 2 L $80 \%$ ethanol by maceration for 48 hours. These were filtered, and the filtrates were dried by rotary evaporation and lyophilization.

\section{Partial Purification}

To determine the appropriate solvent system for separation, crude extracts were subjected to thin layer chromatography. Solvents used were methanol, acetonitrile, ethyl acetate, chloroform, and hexane. Using the best solvent system, the extracts were separated via gradient elution in a silica gel column. For both extracts, the solvents were as follows: ethyl acetate, ethyl acetate-methanol (1:4, 2:3, 3:2, 4:1), methanol, methanol-water $(1: 4,1: 1)$, and water. Fractions were collected and subjected to TLC with ethyl acetate-methanol (5:1) as the solvent system. Fractions with similar retardation factors were pooled together. Pooled fractions of each extract and the crude extracts were subjected to $\alpha$-glucosidase inhibitory and antioxidant assays.

\section{a-Glucosidase Inhibition Assay}

Extracts were prepared at $1.0 \mathrm{mg} / \mathrm{mL}$. In $250 \mu \mathrm{L}$ phosphate buffer ( $\mathrm{pH} 6.8), 100 \mu \mathrm{L}$ of extract or fraction was incubated at room temperature for 5 minutes with $100 \mu \mathrm{L} 2.0 \mathrm{mM}$ $p$-nitrophenyl- $\alpha$-D-glucopyranoside ( $p$-NPG) as substrate for the enzyme. Then $50 \mu \mathrm{L}$ of $1.0 \mathrm{unit} / \mathrm{mL} \alpha$-glucosidase from Saccharomyces cerevisiae was added and the solution was incubated at $37{ }^{\circ} \mathrm{C}$ for 7 minutes. The reaction was terminated by adding $250 \mu \mathrm{L}$ of $0.1 \mathrm{M}$ sodium carbonate. Acarbose was used as the positive control.

Change in absorbance was measured at $405 \mathrm{~nm}$ after termination of the reaction. Percentage inhibition of each fraction was computed as:

$$
\% \text { inhibition }=\frac{C-\left(S_{7}-S_{0}\right)}{C} * 100
$$

where $\mathrm{C}$ refers to the blank control, $\mathrm{S}$ refers to the extracts, subscript 7 refers to absorbance after 7 minutes, and subscript 0 refers to initial absorbance.

The mode of inhibition of the fraction with the highest $\alpha$ glucosidase inhibitory activity was determined using the same procedure described but varying the concentration of p-NPG $(0.8$, $1.0,1.3,1.5,1.8 \mathrm{mM})$. Lineweaver-Burk plots were generated by plotting the reciprocal of the initial reaction rate with respect to the reciprocal of substrate concentration. The initial reaction rate was computed as the rate of formation of $\mathrm{p}$-nitrophenol. The procedure was done first without any inhibitor and then in the presence of $250 \mu \mathrm{g} / \mathrm{mL}$ of the fraction. Maximum velocity $\left(\mathrm{V}_{\max }\right)$ and Michaelis-Menten constant $\left(\mathrm{K}_{\mathrm{m}}\right)$ for both conditions were computed from the Lineweaver-Burk plots.

\section{1,1-Diphenyl-2-picryl-hydrazyl (DPPH) Free Radical Scavenging Assay}

Fractions were prepared to a concentration of $10 \mathrm{mg} / \mathrm{mL}$ and $375 \mu \mathrm{L}$ of this stock solution was added with $375 \mu \mathrm{L} 0.2 \mathrm{mM}$ DPPH in ethanol. Mixture were shaken and incubated in the dark for $30 \mathrm{~min}$. Absorbance was measured at $517 \mathrm{~nm}$ with ascorbic acid as the positive control. Percentage radical scavenging activity of each fraction was computed as:

$$
\% \text { radical scavenging activity }=\frac{C-\left(S_{30}-S_{0}\right)}{C} * 100
$$

where $\mathrm{C}$ refers to blank control, $\mathrm{S}$ refers to the extracts, subscript 30 refers to absorbance after 30 minutes, and subscript 0 refers to initial absorbance.

\section{Iron (II) Chelation Assay}

The iron (II) chelation assay was done by adding $200 \mu \mathrm{L}$ of extract $(10 \mathrm{mg} / \mathrm{mL})$ and $20 \mu \mathrm{L} \mathrm{FeCl}_{2}(2 \mathrm{mM})$ in $740 \mu \mathrm{L}$ solvent. After which, $40 \mu \mathrm{L}$ 3-(2-pyridyl)-5,6-diphenyl-1,2,4-triazine or 
ferrozine $(5 \mathrm{mM})$ was added and the solution was incubated at room temperature for 10 minutes. Absorbance was measured at $562 \mathrm{~nm}$ with quercetin as the positive control. Percentage iron (II) chelating activity of each fraction was computed as:

$$
\% \text { iron chelating activity }=\frac{C-\left(S_{10}-S_{0}\right)}{C} * 100
$$

where $\mathrm{C}$ refers to blank control, $\mathrm{S}$ refers to the extracts, subscript 10 refers to absorbance after 10 minutes, and subscript 0 refers to initial absorbance.

\section{Ferric Reduction/Antioxidant Power (FRAP) Assay}

The FRAP Assay protocols used were given by (Benzie and Strain, 1999).Absorbance was measured at $595 \mathrm{~nm}$. A calibration curve of absorbance versus ferrous sulfate equivalents was prepared and tannic acid was used as the positive control for the assay.

\section{Statistical Analysis}

All measurements were done in triplicate and mean activities and standard deviations were computed. One-Way ANOVA with Tukey post-hoc test was performed to determine the most active fractions.

\section{Phytochemical Screening}

The protocol for phytochemical screening used was the guidelines given by Aguinaldo et al. (2005). Fractions of each extract were spotted on thin-layer silica gel plates and plates were developed in a chamber with chloroform-methanol (5:1). The chromatograms were air-dried and visualized using the reagents stated in the guidelines. Tests for the presence of flavonoids, steroids, phenols, tannins, alkaloids, cardenolides, coumarins, anthraquinones, indoles and sugars were conducted.

\section{RESULT AND DISCUSSION}

After gradient elution with ethyl acetate, methanol, and water, a total of $18015-\mathrm{mL}$ fractions were collected from each extract. From the 180 fractions, the A. bunius crude extract (ABCrude) was pooled into five fractions (AB1, AB2, AB3, AB 4, and $\mathrm{AB} 5$ ) while the $G$. nepalensis crude extract (GNCrude) was pooled into seven fractions (GN1, GN2, GN3, GN4, GN5, GN6, and GN7).These fractions, along with the A. bunius and $G$. nepalensis crude extracts were subjected to the different assays.

For the $\alpha$-glucosidase inhibition assay, a change in absorbance at $405 \mathrm{~nm}$ is attributed to the release of $p$-nitrophenol after hydrolysis of $p$-NPG by the enzyme. Thus, a decrease in absorbance is correlated to an increase in inhibition activity. Figure 1 shows the $\alpha$-glucosidase inhibition activity of the crude extracts and fractions at $1 \mathrm{mg} / \mathrm{mL}$. All G. nepalensis fractions showed inhibitory activity while only fractions $\mathrm{AB} 4$ and $\mathrm{AB} 5$ from A. buniusinhibited the enzyme. Moreover, fractions GN 1, GN 4, GN 5 and GNCrude had comparable activity compared to the positive control Acarbose. $\alpha$-Glucosidase inhibition is important in diabetic patients because these slow down the hydrolysis of polysaccharides and the absorption of free sugars in the intestine. Ultimately, this results in less drastic rise in blood glucose levels and decreased insulin sensitivity (Mogensen, 2007).

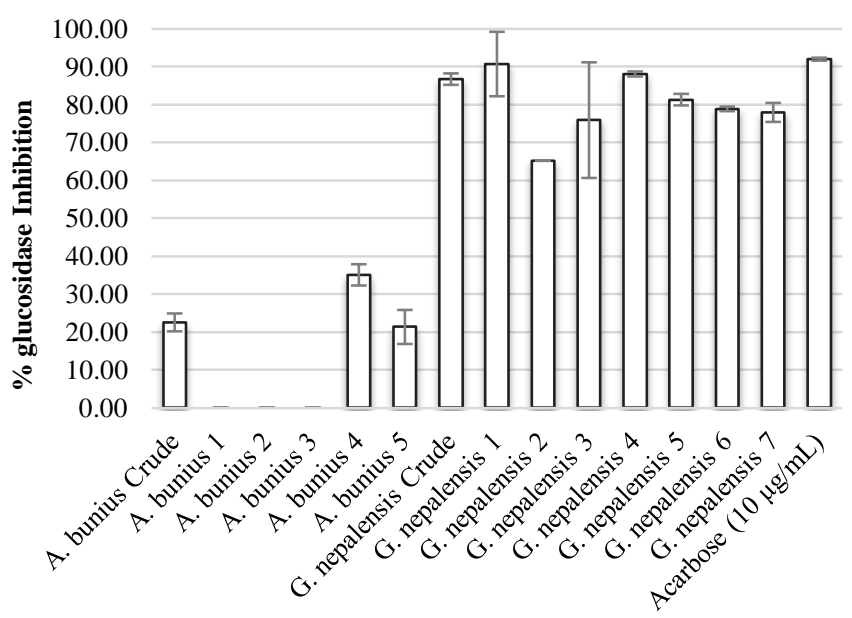

Fig. 1: $\alpha$-glucosidase inhibitory activity of $1 \mathrm{mg} / \mathrm{mL}$ crude extracts and fractions of the A. buniusand G. nepalensis extracts and fractions, with Acarbose as positive control. No inhibition was detected from the A. bunius 1,2 and 3 fractions.

Fraction GN 1 showed the highest activity among all fractions and its possible mode of inhibition was determined. Figure 2 shows the Lineweaver-Burk plots of $\alpha$-glucosidase in the absence and presence of GN 1.

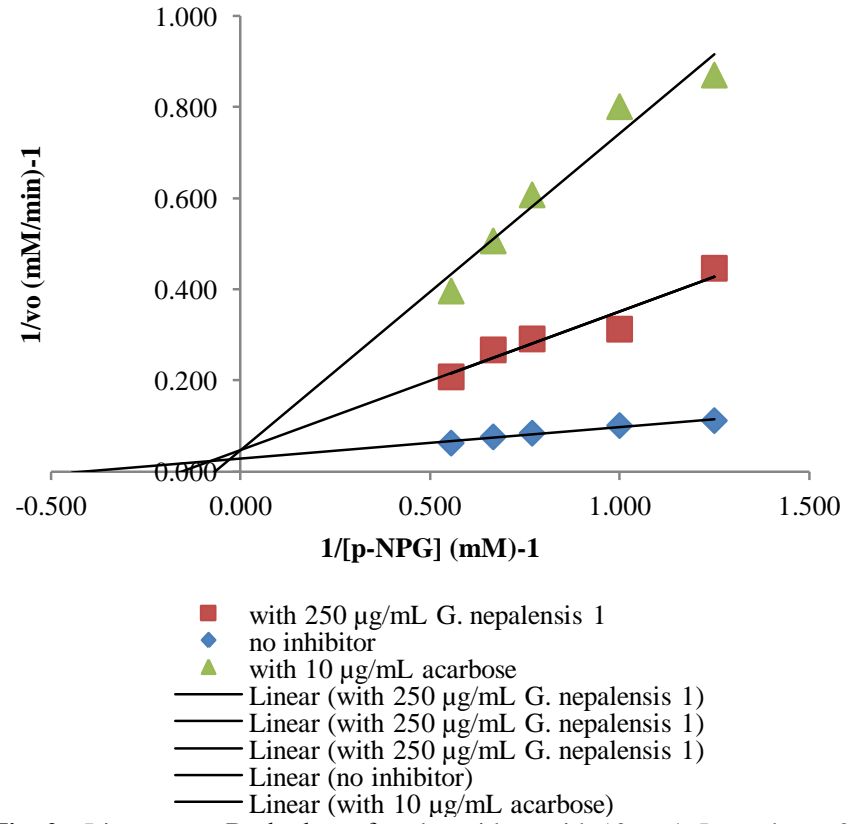

Fig. 2: Lineweaver-Burk plots of $\alpha$-glucosidase with $10 \mathrm{mg} / \mathrm{mL}$ acarbose, 250 $\mu \mathrm{g} / \mathrm{mL} \mathrm{G} 1$, and without any inhibitor.

The increase in $y$-intercept is interpreted as a decrease in $V_{\max }$ of the enzyme caused by $G$. nepalensis 1 (Table 1). GN1 seems to exhibit a mixed mode of inhibition of $\alpha$ - 
glucosidase which is not unexpected because GN1 has not been totally purified.

Table 1: $\mathrm{V}_{\max }$ and $\mathrm{K}_{\mathrm{m}}$ values of $\alpha$-glucosidase with and without G. nepalensis .

\begin{tabular}{lcc}
\hline Condition & $\mathbf{K}_{\mathbf{m}}(\mathbf{m g} / \mathbf{m L})$ & $\mathbf{V}_{\mathbf{m a x}}(\mathbf{m g} / \mathbf{m L} \bullet \mathbf{s})$ \\
\hline without inhibitor & 2.431 & 35.03 \\
with G. nepalensis 1 & 6.551 & 21.47 \\
with Acarbose & 14.947 & 21.28 \\
\hline
\end{tabular}

For the antioxidant activities, three assays were performed: DPPH assay, iron (II)-chelating assay and FRAP assay. Figure 3 shows the radical scavenging activity of crude extracts and fractions via DPPH assay. All A. bunius fractions showed high radical scavenging activity with $\mathrm{AB} 1$ having the highest. Compared to the positive control Ascorbic acid, all A. bunius extract and fractions, as well as GN 1, 2 and 4, had comparable activity.

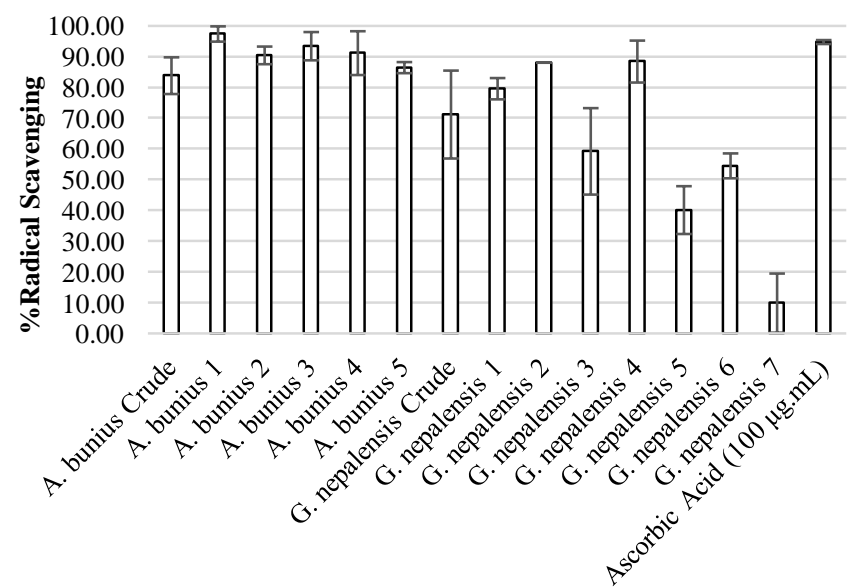

Fig. 3: Free radical scavenging activity of $10 \mathrm{mg} / \mathrm{mL}$ crude extract and fractions of the A. bunius and G. nepalensis determined via DPPH assay using Ascorbic acid positive control.

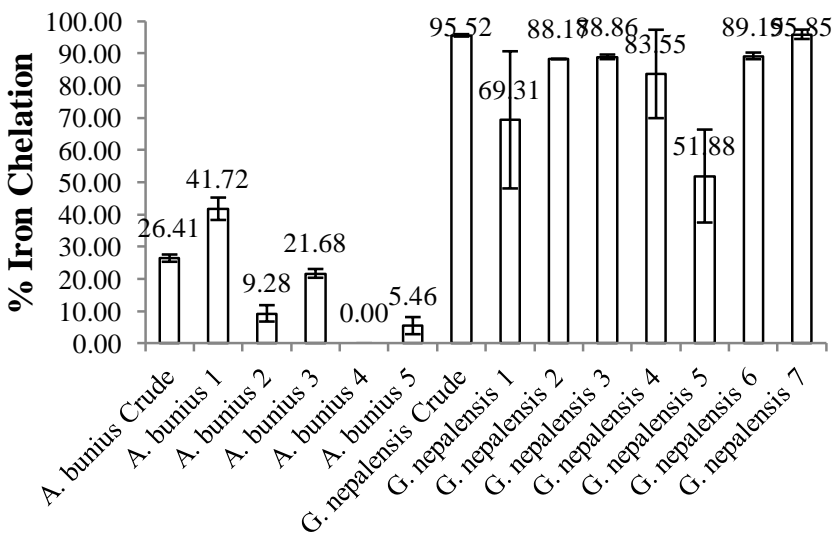

Fig. 4: Iron (II) chelating activity of $10 \mathrm{mg} / \mathrm{mL}$ crude extracts and fractions fractions of the A. bunius and G. nepalensis.

On the other hand, Figure 4 shows the iron (II) chelating activities of the crude extracts and fractions. Most of the $G$. nepalensis fractions showed high iron chelating activity with GN 7 having the highest activity among all fractions. AB 4 was the only fraction from $A$. bunius with no iron chelating activity. Iron chelation is an important mode of antioxidant activity particularly because the ferrous ion is involved in the Fenton reaction, which produces the hydroxyl radical, a very strong reactive oxygen species (ROS). With ferrous ions chelated to certain compounds in the extracts, the Fenton reaction is prevented.

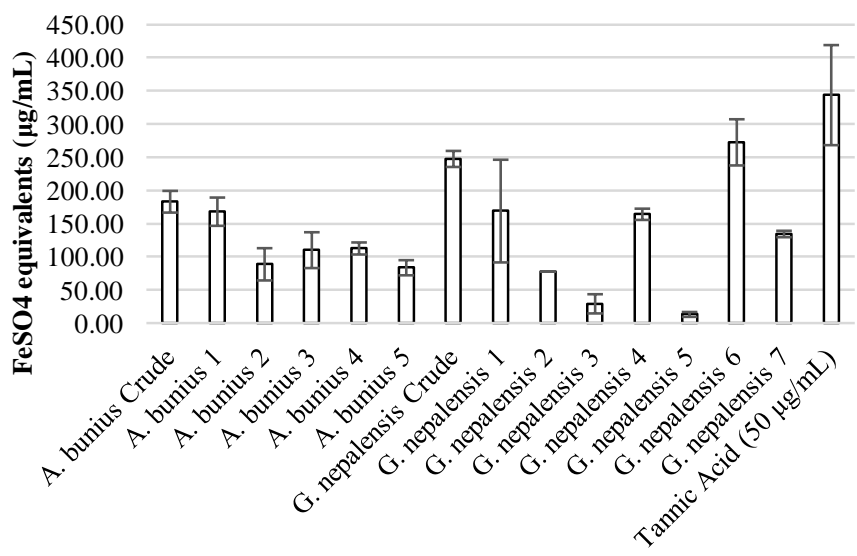

Fig. 5: Ferric reduction activity of $1 \mathrm{mg} / \mathrm{mL}$ crude extracts and fractions of the A. buniusand G. nepalensis expressed as $\mathrm{FeSO}_{4}$ equivalents, with Tannic acid positive control.

Finally, Figure 5 shows the ferric ion reducing power of the crude extracts and fractions in terms of the ferrous sulfate equivalents in the reacted solution. All fractions exhibited ferric reduction with GN 6 having the highest activity. Moreover, only GN Crude and GN 6 had comparable activity with the positive control Tannic acid.Any substance with a higher reducing potential than ferric ion will reduce this to ferrous ion. In the process, the compound is oxidized and prevents the oxidation of biological structures (Benzie and Strain, 1999). It is to be noted that ferrous ions are involved in the production of hydroxyl radicals. Thus, the iron chelating activity of the extracts comes hand in hand with ferric reduction.

Table 2: Results of phytochemical screening tests. Legend: '†': Positive; '-': Negative.

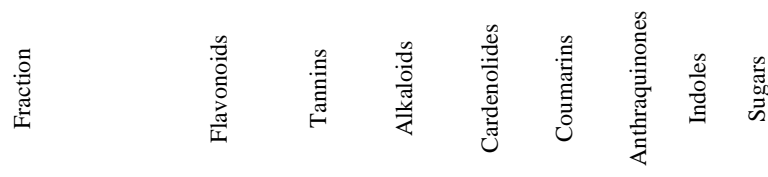

\begin{tabular}{lllllllll}
\hline A. bunius Crude & + & + & - & - & - & - & - & + \\
A. bunius 1 & + & + & - & - & - & - & - & - \\
A. bunius 2 & + & + & - & - & - & - & - & - \\
A. bunius 3 & + & + & - & - & - & - & - & + \\
A. bunius 4 & + & + & - & - & - & - & - & + \\
A. bunius 5 & + & + & - & - & - & - & - & + \\
G. nepalensis Crude & + & - & - & - & + & - & + & + \\
G. nepalensis 1 & + & - & - & - & - & - & - & + \\
G. nepalensis 2 & + & - & - & - & - & - & - & - \\
G. nepalensis 3 & + & - & - & - & - & - & - & - \\
G. nepalensis 4 & + & - & - & - & - & - & + & - \\
G. nepalensis 5 & - & - & - & - & - & - & + & - \\
G. nepalensis 6 & - & + & - & - & + & - & - & - \\
G. nepalensis 7 & - & + & - & - & - & - & - & - \\
\hline
\end{tabular}


Phytochemical screening revealed the presence of tannins and flavonoids to be common among the fractions (Table 2). The phytochemical classes found in the fractions with highest activity can be responsible for such activity. GN1 and AB1 contained flavonoids and this might be responsible for the high $\alpha$-glucosidase inhibitory activity in GN1 and high antioxidant activity in the other fractions as observed in other studies (Pereira et al., 2011; Pietta, 2000).AB1 and GN7 have been found to contain tannins which have been shown to be efficient in free radical scavenging, iron chelation, and ferric reduction (Gulcin et al., 2010). In addition to tannins, GN6 contains coumarins which have been shown to reduce ferric ions effectively (Mladěnka et al., 2010). It appears that the role of phenolic compounds is important in the $\alpha$ glucosidase inhibitory and antioxidant activity of plants.

\section{CONCLUSION}

This study demonstrates the antioxidant and $\alpha$ glucosidase activities of partially purified A. bunius fruit and $G$. nepalensis leaf extracts in vitro. The group recommends testing the inhibition effects against other enzymes (e.g. $\alpha$-amylase) or testing the extracts in vivo in hyperglycemic rats. Additionally, it should also be a goal to isolate the active components for structure elucidation and chemical synthesis, and use them as possible antidiabetic drug candidates.

\section{REFERENCES}

Abdul-Ghani MA, Norton L, Defronzo RA. Role of sodiumglucose cotransporter 2 (SGLT 2) inhibitors in the treatment of type 2 diabetes. Endocr Rev, 2011; 32(4): 515-531.

Aguinaldo AM, Espeso EI, Guevara BQ, Nonato MG. 2005. A guidebook to plant screening: phytochemical and biological. Manila City, Philippines: UST Publishing House.

Algariri K, Meng KY, Atangwho IJ, Asmawi MZ, Sadikun A, Murugaiyah V, Ismail N. Hypoglycemic and anti-hyperglycemic study of Gynura procumbens leaf extracts. Asian Pac J Trop Biomed, 2013; 3(5): 358-366.

Apea-Bahl FB, Hanafi M, Dewi RT, Fajriah S, Darwaman A, Artanti N, Lotulung P, Ngadymang P, Minarti B. Assessment of the DPPH and $\alpha$-glucosidase inhibitory potential of gambier nad qualitative identification of major bioactive compound. J Med Plants Res, 2009; 3(10):736-757.

Benzie IFF, Strain JJ. Ferric reducing antioxidant power assay, direct measure of total antioxidant activity of biological fluids and modified version for simultaneous measurement of total antioxidant power and ascorbic acid concentration. Method Enzym, 1999; 299: 15-27.

Bonnefont-Rousselot D. The role of antioxidant micronutrients in the prevention of diabetic complications. Treat Endocrinol, 2004; 3(1): $41-52$.

Chang CL, Lin Y, Bartolome AP, Chen YC, Chiu SC, Yang WC. Herbal therapies for type 2 diabetes mellitus: chemistry, biology, and potential application of selected plants and compounds. Evid Based Compl Alt Med, 2013; 2013:378657.

Deng XY, Chen YS, Zhang WR, Chen B, Qiu XM, He LK, Mu LL, Yang CH, Chen R. Polysaccharide from Gynura divaricate modulates the activities of intestinal disaccharidases in streptozotocin-induced diabetic rats. Br J Nutr, 2011; 106(9): 1323-1329.

Garber AJ. Long-acting glucagon-like peptide 1 receptor agonists. Diabetes Care, 2011; 34(Suppl. 2): S279-S284.

Gülçin I, Huyut Z, Elmastas M, Aboul-Enein HY. Radical scavenging and antioxidant activity of tannic acid. Arab J Chem, 2010; 3(1): 43-53.
Kawamori R, Tajima N, Iwamoto Y, Kashiwagi A, Shimamoto K, Kaku K. Voglibose for prevention of type 2 diabetes mellitus: a randomized, double-blind trial in Japanese individuals with impaired glucose tolerance. Lancet, 2009; 373(9675): 1607-1614.

Kimmel B, Inzucchi SE. Oral agents for type 2 diabetes: an update. Clin Diabetes, 2005; 23(2): 64-76.

Lamba SS, Buch KY, Lewis H III, lamba J. Phytochemicals as potential hypoglycemic agents. Stud Nat Prod Chem, 2000; 21(B): 457 496.

Lawag IL, Aguinaldo AM, Naheed S, Mosihuzzaman M. $\alpha$ gluosidase inhibitory activity of selected Philippine plants. J Ethnopharmacol, 2012; 144(1): 217-219.

Li WL, Ren BR, Min-Zhuo, Hu Y, Lu CG, Wu JL, Chen J, Sun S. The anti-hyperglycemic effect of plants in genus Gynura Cass. Am J Chin Med, 2009; 37(5): 961-966.

Liu W, Yu Y, Yang R, Wan C, Xu B, Cao S. Optimization of total flavonoid compound extraction from Gynura medica leaf using response surface methodology and chemical composition analysis. Int $\mathbf{J}$ Mol Sci, 2010; 11(11): 4759-4763.

Misbah H, Aziz AA, Aminudin N. Antidiabetic and antioxidant properties of Ficus deltoidea fruit extracts and fractions. BMC Comp Alt Med, 2013; 13(118).

Mladěnka P, Macókovó K, Zatloukalovó L, Rehókovó Z, Singh BK, Prasad AK, Parmar VS, Jahodór L,Hrdina, Saso L. In vitro interactions of coumarins with iron. Biochimie, 2010; 92(9): 1108-1114.

Mogensen CE. 2007. Pharmacotherapy of diabetes. In: Mogensen CE, ed. Pharmacotherapy of diabetes: new developments. USA: Springer US 277-281.

Montonen J, Knekt P, Järvinen R, Reunanen A. Dietary antioxidant intake and risk of type 2 diabetes. Diabetes Care, 2004; 27(2): $362-366$

Pereira DF, Cazarolli, LH, Lavado C, Mengatto V, Fiqueiredo MS, Guedes A, Pizzolatti MG, Silva FR. Effects of flavonoids on $\alpha$ glucosidase activity: potential targets for glucose homeostasis. Nutri, 2011; 27(11-12): 1161-1167.

Phung OJ, Sood NA, Sill BE, Coleman CI. Oral anti-diabetic drugs for the prevention of type 2 diabetes. Diabetic Med, 2011; 28(8): 948-964 1035-1042.

Pietta PG. Flavonoids as antioxidants. J Nat Prod, 2000; 63(7):

Shihabudeen HMS, Priscilla DH, Thirumurugan K. Cinnamon extract inhibits $\alpha$-glucosidase activity and dampens postprandial glucose excursion in diabetic rats. Nutri Metab, 2011; 8(46): 1-11.

Singh J, Cumming E, Manoharan G, Kalasz H, Adeghate E. Medicinal chemistry of the anti-diabetic effects of Momordica charantia: active constituents and modes of actions. Open Med Chem J, 2011; 5(Suppl 2): 70-77.

Tan C, Wang Q, Luo C, Chen S, Li Q, Li P. Yeast $\alpha$ glucosidase inhibitory phenolic compounds isolated from Gynura medica leaf. Int J Mol Sci, 2013; 14(2): 2551-2558.

Wang Y, Xiang L, Wang C, Tang C, He X. Antidiabetic and antioxidant effects and phytochemicals of mulberry fruit (Morus alba L.) polyphenol enhanced extract. PLoS One, 2013; 8(7): e71144.

White JR. Dipeptidyl peptidase-IV inhibitors: pharmacological profile and clinical use. Clin Diabetes, 2008; 26(2): 53-57.

Whiting DR, Guariguata L, Weil C, Shaw J. IDF diabetes atlas: global estimates of the prevalence of diabetes for 2011 and 2030. Diabetes Res Clin Pract, 2011; 92: 311-321.

Wilcox G. Insulin and insulin resistance. Clin Biochem Rev, 2005; 26(2): 19-39.

\section{How to cite this article:}

Quiming N, Asis JL, Nicolas M, Versoza D, Alvarez MR. In vitro $\alpha$-glucosidase inhibition and antioxidant activities of partially purified Antidesma bunius fruit and Gynura nepalensis leaf extracts. J App Pharm Sci, 2016; 6 (05): 097-101. 